Portland State University

PDXScholar

Fall 11-8-2018

\title{
Judgments of Lethal Risk: a Comparison of Visual and Narrative Stimuli
}

Derek Anthony Bonniksen

Portland State University

Follow this and additional works at: https://pdxscholar.library.pdx.edu/open_access_etds

Part of the Communication Commons Let us know how access to this document benefits you.

\section{Recommended Citation}

Bonniksen, Derek Anthony, "Judgments of Lethal Risk: a Comparison of Visual and Narrative Stimuli" (2018). Dissertations and Theses. Paper 4709.

https://doi.org/10.15760/etd.6593

This Thesis is brought to you for free and open access. It has been accepted for inclusion in Dissertations and Theses by an authorized administrator of PDXScholar. Please contact us if we can make this document more accessible: pdxscholar@pdx.edu. 
Judgments of Lethal Risk:

A Comparison of Visual and Narrative Stimuli

by

Derek Anthony Bonniksen

A thesis submitted in partial fulfillment of the requirements for the degree of

\section{Master of Science}

in

Communication

Thesis Committee:

Lauren B. Frank, Chair

Cynthia-Lou Coleman

Brianne Suldovsky

Portland State University

2018 
(C) 2018 Derek Anthony Bonniksen 


\begin{abstract}
The nature of how we make judgments has received a great deal of attention in the last few decades. Risk communication research has indicated that risk-related messages can elicit affective responses in audiences, which can then have a significant impact on how such audiences judge risk in general. Using a 2 x 2 between-subjects factorial design, this study found that, contrary to Johnson and Tversky's (1983) findings, presenting narratives about lethal risk does not influence readers' judgments about the frequency that risks occur, nor do such narratives influence participant worry levels about the lethal risks, more generally. Additionally, the inclusion of an image alongside both positively and negatively valenced narratives demonstrated no effect on frequency estimates or worry levels. These experimental conditions, although revealing no significant effects, did illuminate the relationship between judgments of risk frequency and corresponding worry levels. Implications for future research on affect and judgments of risk, as well as the relationship between judgments of control and risk assessments, are discussed.
\end{abstract}




\section{Dedication}

This study is dedicated to my family. My mother and father, Gail and Bill Bonniksen, have been endlessly patient and supportive throughout my decision to resume my education, attend graduate school, and the arduous process of completing my thesis. I cannot begin to express how much their support has meant to me. My brother, Matthew, and his wife, Celeste, also deserve a great deal of thanks for their support as a sounding board for any frustrations I felt compelled to express. And finally, my beautiful niece, Maya, remains a source of optimism that always helps remind me what is important. 


\section{Acknowledgments}

I must begin by acknowledging Dr. Lauren Frank, my thesis advisor. Her responsiveness to any of my needs during this process has been nothing short of incredible. As my progress has ebbed and flowed, Dr. Frank has always stayed positive and treated me with respect and good humor. Her guidance has always made me feel that I could complete this study, no matter my level of frustration. I would also like to thank the rest of my committee, Dr. Cynthia Coleman and Dr. Brianne Suldovsky, for always being open to entertaining my questions, regardless of how ridiculous they may have been. Every member of this committee has shown me great kindness and helped me clarify my thoughts and engage my curiosity. Thanks to all. 


\section{Table of Contents}

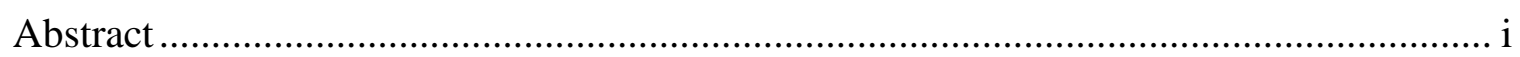

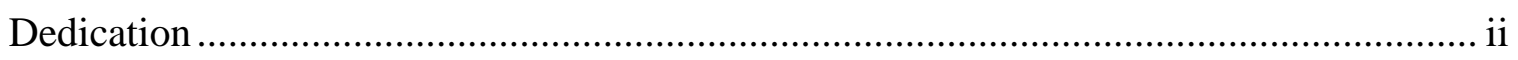

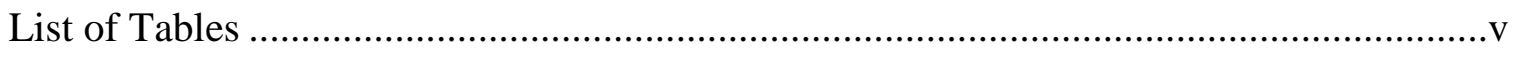

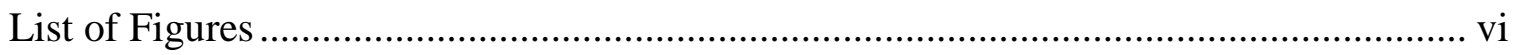

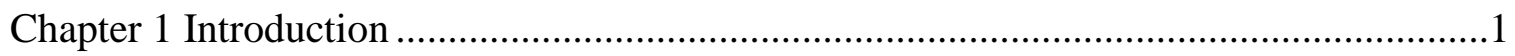

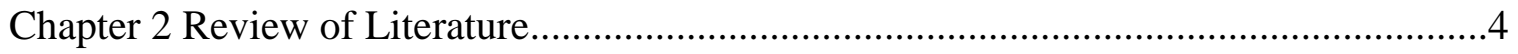

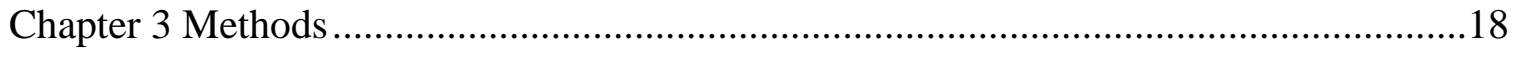

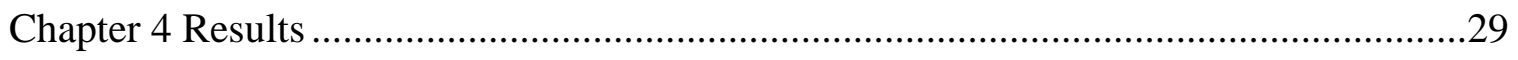

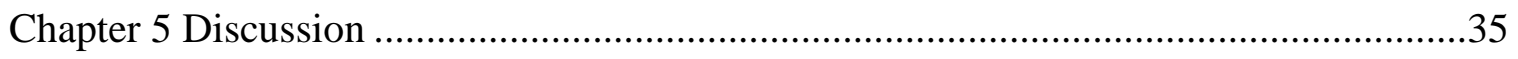

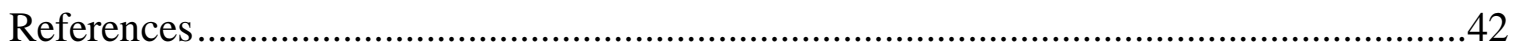

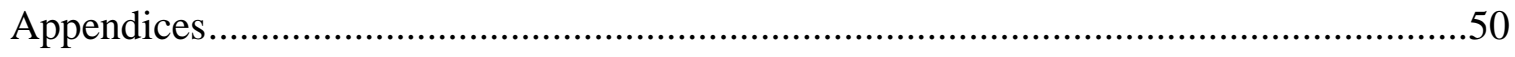

Appendix A: Experimental Stimuli .......................................................50

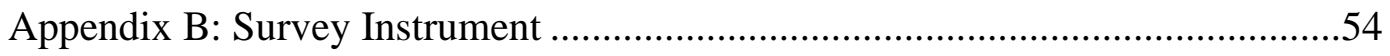

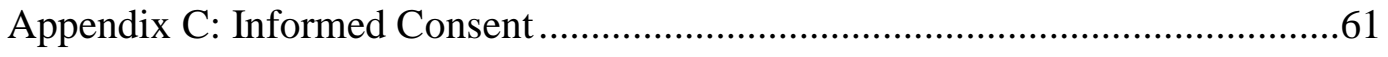




\section{List of Tables}

Table 1 Two by Two Experimental Design............................2 21

Table 2 Local Risk Frequency Estimates...................................31

Table $3 \quad$ Global Risk Frequency Estimates..................................33

Table $4 \quad$ Frequency Estimates and Worry Level Correlations..................34 


\section{List of Figures}

Figure 1 Additive Tree Representation of Risk Similarities.................19

Figure 2 Experimental Stimulus: Positive Image.......................23

Figure 3 Experimental Stimulus: Negative Image.......................... 25 


\section{Chapter One: Introduction}

It should come as no surprise that humans are prone to errors in judgment. Because we are often limited in the information to which we have access, we frequently rely on either incomplete evidence, emotional cues, or both when assessing the world we inhabit. Such errors are particularly powerful in terms of how humans judge risk. While certainly capable of applying logic to potentially risky situations and behaving accordingly, our states of mind and the manner in which messages of risk are presented often short-circuit logic and lead us to over or underestimate risk. These imperfections of cognition are commonplace and are often no cause for concern. In some instances, however, such cognitive failures compel actors to pursue unwarranted actions-actions which may have been resisted had a risk been properly assessed.

Recurring examples of such errors in judgment are demonstrated in public polling data. For example, public opinion surveys demonstrate that Americans tend to believe that violent crime rates are rising even though official data suggest the opposite. "These polling trends stand in sharp contrast to the long-term crime trends reported by the FBI

and BJS [Bureau of Justice Statistics]. Both agencies have documented big decreases in violent and property crime rates since the early 1990s, when U.S. crime rates reached their peak" (Gramlich, 2016, para 10). In the same vein, the citizenry overestimates the danger posed by terrorist attacks in the United States in comparison with a seemingly endless list of other, more frequently occurring mortal dangers. For example, Politifact (2015) noted that, between 2005 and 2015, extremist attacks claimed the lives of 71 
Americans. During that same period, gun deaths accounted for over 300,000 deaths. This incongruence between the degrees of risk among several risk categories is important

The effort to gain a fuller understanding of how humans make errors when judging risk is not simply an academic exercise. The better we understand how and why such errors occur, the more likely we are to develop effective strategies for steering the broader public toward reasonable assessments of the level of risk carried by a multitude of potential hazards. In discussing the impact that acts of terrorism have on the public's judgment of risk, Cass Sunstein (1980) writes:

Hence an act of terrorism will have a large number of "ripple effects" [...] including a demand for legal interventions that might not reduce risks and that might in fact make things worse. Consider, for example, the possibility that extensive security precautions at airports will lead people to drive rather than to fly; because flying is much safer than driving, such precautions might sacrifice many lives on balance. (p. 2)

In other words, managing our collective judgment of risk is important on a practical level. Unwarranted fears about low-probability events can have a negative practical impact. So, too, can the underestimation of such events create a collective apathy towards preparedness and a rejection of reasonable policies designed to mitigate potential harm. The purpose of this thesis is to examine how affect influences judgments of risk and the degree to which varying message features play a role in guiding such judgments.

In chapter 2 , this study will present a review of literature to provide a foundation for influential elements in how we judge risk. Chapter 3 will detail the methods used in 
the effort to properly measure the constructs, as well as the participants who have taken part in the study. Chapter 4 will report the results of the study, which indicated that affect had no impact on participants' worry levels or frequency estimates. Finally, chapter 5 will use these results as a way of broadening the discussion concerning implications for research on affect and judgments of risk, limitations of the methodology used, and how this research can be extended in future studies. 


\section{Chapter 2: Literature Review}

\section{Judgments of Risk}

The term risk has been conceptualized in several different ways, largely dependent upon the domain in which risk is being studied. As it will be referred to in this study, the term risk simply refers to the uncertainty of outcomes or the extent to which outcomes are more or less probable (Folkes, 1988; Harrington \& Kerr, 2017; Slovic, Fischhoff, \& Lichtenstein, 1980; Starr, 1969;). Risk researchers, particularly those who operate in the domains of psychology (Arrow, 1982; Lopes, 1987; Rottenstreich \& Hsee, 2001), decision-making (Kim, Ferrin, \& Rao, 2008; Lu, Hsu, \& Hsu, 2005), and communication (Coleman, 1993; Harrington \& Kerr, 2017; Wray, Kreuter, Jacobsen, Clements, \& Evans, 2004), approach risk analysis from a different perspective than those who operate in finance, for example. Rather than focusing on mathematical probabilities, those who work in social or psychological fields address the subjective nature of risk. The estimated severity or frequency of a given hazard will vary between subjects and tends to vary depending upon those subjects' affective states (Lichtenstein, Slovic,

Fischhoff, Layman, \& Combs, 1978). Researchers in sociology and psychology recognize that such fundamental subjectivity requires a research approach which extends beyond mathematical probabilities.

It is important to first understand how research has integrated cognitive heuristics into explorations regarding judgments of risk. The term heuristics refers to the mental shortcuts that individuals use when making cognitively complex assessments (Tversky \& Kahneman, 1975). Before heuristics were given due credit for their influence on 
judgments of risk, a considerable volume of scholarship asserted that humans rely primarily on rational evaluations and logic when assessing the potential costs and benefits of a given course of action (Fishburn, 1970; Mossin, 1968; Pratt, 1964). Judgments of risk were once considered a function of primarily logical, deliberative thought processes. That perspective is most synonymous with expected utility theory (EUT), which postulates that decision-making and risk assessment are based on a deliberative comparison between potential costs or benefits of a given action (Mongin, 1997). Expected utility theory research has traditionally examined risk through a financial lens.

Such calculations have been considered by some, however, to be inadequate descriptions of the process by which humans evaluate risk under uncertainty. As Paul Slovic puts it, "Reliance on 'the feeling of risk' was essential to human survival in the course of evolution, and even today, feelings serve as a compass that guides most of our daily decisions" (Slovic, 2016, p. 29). To his point, imagine walking through grass, and your eye catches something that appears to "slither" near your feet. The natural reaction is something that most anyone in this situation would have- - to jump back. This reaction is not the result of judiciously considering the snake population in the area and the probability of it being a poisonous or aggressive variety of snake. It is an instant reaction and one that supersedes deliberative information processing. What this example suggests is that human cognition has an evolutionary, purely visceral component. Human cognition, however, does not live only in a world of instinct. We can deliberate over the decisions we make and often do, provided that we have the time and all necessary information. But we employ both of these systems often simultaneously by using 
cognitive shortcuts in order to make assessments quickly without exerting too much cognitive effort (Kahneman, 2011).

The distinction between judgment and perception is not a simple one to convey. Risk communication researchers routinely use the terms interchangeably ( Lichtenstein, et al., 1978; Slovic, 2016), although some have argued that the two are not synonymous, arguing that perception is a sensory precursor to judgment (Coleman, 1993; Dunwoody \& Neuwirth, 1991). Firestone and Scholl (2015) suggest that sensory cues are first processed and then judgments can be made according to those sensory inputs. Firestone and Scholl (2015) argue, for example, that "whereas we can directly see visual properties such as the color or size of a banana, we can only infer, conclude, or judge that the banana is expensive or is grown in South America" (p. 1217). This study is aimed at capturing the second piece of the above example—-the inferences and judgments—and will therefore refer to judgments of risk accordingly.

\section{Cognitive Heuristics}

In the mid-1950s, Herbert Simon (1992) proposed that, because there are constraints on humans' ability to consider every piece of relevant information when making a decision or assessment, we rely on cues to inform our intuition. In expanding on that notion, he wrote the following:

In everyday speech, we use the word intuition to describe a problem-solving or question-answering performance that is speedy and for which the expert is unable to describe in detail the reasoning or other process that produced the answer. The situation has provided a cue; this cue has given the expert access to information 
stored in memory, and the information provides the answer. Intuition is nothing more and nothing less than recognition. (p. 155)

When confronted with a risk or a situation that demands a decision be made, the impossibility of having all pertinent information forces a person to rely on heuristics. Reliance on heuristics is a necessary shorthand that, although often useful, leaves us susceptible to errors in judgment.

Extant research specifically suggests that the influence of two cognitive heuristics—affect and availability—are particularly influential in how we judge risk (Finucane, Alhakami, Slovic, \& Johnson, 2000; Kahneman, 2011; Slovic, 2016; Slovic, Peters, Finucane, \& MacGregor, 2005; Tversky \& Kahneman, 1975).

The availability heuristic. The availability heuristic refers to the ease with which a person can recall instances of an occurrence or a class of occurrences (Tversky \& Kahneman, 1973). In terms of probability assessments, the strength of the associative bond between a potential external event and the ease with which a person can retrieve an example of a similar event has been found to influence the frequency that a person estimates such events occur generally (Tversky \& Kahneman, 1973, pp. 208-209). Experiments on matters as wide-ranging as participants' judgments of their own level of assertiveness (Schwarz et al., 1991), the frequency with which particular letters of the alphabet appear in the first position in a word versus the third position (Tversky \& Kahneman, 1973), and investor predictions about future earnings (Moser, 1989) suggest that this heuristic is routinely employed in the process of making predictive judgments. 
Considerable research supports the validity of this heuristic. For example, when asked to judge the frequency of pairs of lethal events (e.g., strokes vs. accidents, tornadoes vs. asthma, lightning vs. botulism), Lichtenstein et al. (1978) found that respondents consistently estimated the less frequent events to occur more frequently than the event with which it was paired. Asthma causes approximately 20 times the number of deaths than tornadoes, yet participants judged tornadoes to be a more frequent cause of death (1978, p. 555). The authors assert that conjuring an image of a tornado is much easier than recalling an "image" of asthma and, therefore, participants overestimated tornado-related fatalities. In other words, tornadoes are more readily available in one's memory than are asthma attacks.

In another study, Keller, Siegrist, and Gutscher (2006) found that, when presented with statistical probabilities of floods, participants who had personally experienced a flood judged flood risks as greater than those who had not. "Persons who stored images or narratives about floods in their memories", the authors write, "perceived the same probability information differently from people without such memories" (p. 636).

Sherman et al. (1985) found particularly illuminating results in their study of how imagination relates to availability. The researchers asked one group of participants (group A) to imagine a set of symptoms that could easily be envisioned (e.g., headaches, muscle aches) and were told that they are indicative of a disease called "Hyposcenia-B." A second group (group B) was instructed to imagine a set of symptoms that would be more difficult to envision (e.g., liver inflammation, disorientation). The results of the experiment revealed that members of group A rated their chances of contracting 
"Hyposcenia-B" significantly higher than those in group B (Sherman et al., 1985, p. 123), suggesting that the ease or difficulty of imagining symptoms also impacts judgments of probability.

Ease of retrieval is not only a product of first-hand experience, however. Exposure to mediated narratives or being asked to imagine negative outcomes have also been found to impact individuals' assessments of risk. For example, if a particular cause of death is reported more often than a different, yet equally frequent cause of death, consumers of that source of information will, sometimes drastically, misjudge the frequency of the two causes relative to one another (Combs \& Slovic, 1979). The manner in which stories are reported and the frequency with which particular classes of stories are reported (e.g., natural disasters, crime, corruption) have an impact on readers' judgments of frequency. The "how" and the "how often" with regard to news reporting influences both affect and availability.

As Tversky and Kahneman (1975) describe it, "In general, availability is a useful clue for assessing frequency or probability, because instances of large classes are recalled better and faster than instances of less frequent classes" (p. 15). Most importantly, the easier it is to recall a class or category of events, the more likely an individual is to overestimate the frequency of such events (Tversky \& Kahneman, 1975, p. 15).

The affect heuristic. The affect heuristic refers to responses to stimuli based on affective cues; affect can be described as what scholar Paul Slovic (2004) calls, "a 'faint whisper of emotion"” (p. 312). In other words, the way that we feel about a stimulus-the "goodness" or "badness" of that feeling_-informs our judgment of that stimulus. 
Although previous research has tended to use affect, mood, feelings, and emotion interchangeably (Kahneman, 2011; Slovic \& Peters, 2006; Wright \& Bower, 1992), some have argued that these terms, specifically emotion and affect, are distinct and should be treated as such (Massumi, 1995; Schwarz \& Clore, 2007).

The difficulty in sufficiently defining affect is evidenced by Slovic (2004) himself. Even after describing affect as a "faint whisper of emotion", he goes on to use emotion and affect interchangeably in the same article, effectively dispensing with the "faint whisper" portion of his own definition. Those scholars who assert that these terms should not be considered synonymous (Massumi, 1995; Schwarz \& Clore, 2007) suggest that emotion is a more nuanced term than affect and is not simply a binary-positive or negative—state. Schwarz and Clore (2007) argue that, "All emotions are affective, but not all affective things are emotions" (p. 385). They assert that emotions, unlike affective states, have clearly identifiable referents or causes. In other words, if a person is angry, that person can likely identify the source of that anger-they are angry at something. If that person is experiencing a negative affective state, they are in a bad mood (p. 386).

One particular emotion that is most applicable to this study is worry. Worry has been identified as a key contributor to how risk is assessed and one's perception of risk controllability (Freeston, Rhéaume, Letarte, Dugas, \& Ladouceur, 1994). Though it could reasonably be described as either a dimension or contributor to affective states (Borkovec, Ray, \& Stober, 1998), worry is an essential indicator of how we assess uncertainties such as disaster, disease, and unforeseeable accidents. Research has suggested that risk probability judgments are positively associated with both worry levels 
and desire for action that would mitigate various risks (Baron, Hershey, \& Kunreuther, 2000).

While this contention- that affect and specific emotions such as worry should be considered separate concepts - is not without merit, decades of researchers have used the terms interchangeably. Given that, this study will also treat emotion and affect as synonymous concepts.

For many years, affect was neglected in explanatory models of risk judgments. Zajonc (1980), one of the first to recognize the key role that affect plays in decision making and cognition, more generally, wrote the following:

We may completely fail to notice a person's hair color or may hardly remember what it was shortly after meeting the person. But we can seldom escape the reaction that the person impressed us as pleasant or unpleasant, agreeable or disagreeable, as someone to whom we were drawn or someone by whom we were repelled. (p. 6)

Although Zajonc, in this passage, is referring to an interpersonal encounter, the salience of affect holds true in nearly every assessment humans make. We attach a positive or negative valence-consciously or unconsciously — to the events and situations we encounter.

Narrative impact. The impact of narrative exposure has received a fair amount of study as it relates to judgments of risk. In 1983, Tversky and Johnson conducted an experiment that explored such impacts. Importantly, they noted that, "One characteristic that distinguishes judgments about risks from other estimates...is that they seldom occur 
in an emotionally neutral context" (pp. 20-21). The authors theorized that a person's affective response to a risk-related narrative would influence his or her judgment of that risk. They proposed that the affective response elicited by a story about a specific hazard may inflate a reader's estimate for the prevalence of that hazard. Their experiment, therefore, sought to better understand the connection between a person's frequency estimates of specific risks and his or her exposure to detailed descriptions of an individual's death due to a cause related to one of the risks. "Like many newspaper stories," the authors wrote, "our accounts described details of the tragic incident, but gave no information about its prevalence" $(1983$, p. 3). They predicted that exposure to such accounts would increase both the subjects' level of worry about the specific hazard detailed in the account as well as the subjects' estimation of its frequency relative to the control condition. As they put it, they thought that the stories would produce a local effect. In other words, estimates related to the hazard described—as well as closelyrelated hazards-would be higher for the experimental condition than for the control condition, they predicted. To their surprise the experimental condition produced a global effect, meaning that experimental subjects reported higher rates of worry and frequency estimates even for unrelated risks noted in the questionnaire than did those in the control condition. The participants' affective response resulted in a generalized impact on their assessments of lethal risks-from leukemia to lightning strikes to terrorism (the questionnaire included a total of eighteen risk items). What the authors concluded from these results is that the mood induced by the detailed narrative had a global effect on respondents' frequency estimates (Johnson \& Tversky, 1983, p. 29). "Risks that are 
closely linked to the story should be influenced more than unrelated risks," they noted, "contrary to the present findings" (p. 30).

The results imply that, even though these tragic accounts were included in a set of three (fictional) newspaper articles, the narrative impact of the tragedy described was sufficient to influence the affective disposition of the respondents. In other words, the narrative description of a tragic event resulted in a negative affective response toward the cause of the tragedy, which carried over to other risks, regardless of their relationship to the specific risk described in the story—-the "target risk", as they described it. Johnson and Tversky (1983) suggest that, "The results give rise to the hypothesis that we tend to make judgments that are compatible with our current mood, even when the subject matter is unrelated to the cause of that mood" (1983, p. 16).

Affect and availability are certainly not independent of one another. It is conceivable that availability is not simply influenced by the ease with which a class is recalled or imagined. The affective component may very well "tag" those memories or imaginings, making them more salient and increasing the strength of availability (Slovic et al., 2004). For example, if one were exposed to a news item that detailed the symptoms of a particularly deadly infectious disease, that story would likely result in a powerful "imprint" on that person's memory—in this case, a negative imprint. Subsequent references to that disease would therefore more easily activate the affective dimension of a memory, the reader's affective response to the initial story. Slovic et al. (2004) refers to the catalogue of such images in a person's mind as their "affect pool", with each image “...tagged or marked to varying degrees with affect" (p. 314). 
Our tendency to disconnect our affective state from risk assessments, as described by Johnson and Tversky (1983), is in line with Zajonc's (1980) assertion that, “The dismal failure in achieving substantial attitude change through various forms of communication or persuasion is another indication that affect is fairly independent and often impervious to cognition" (p. 158). This point was backed up by Johnson and Tversky's (1983) findings that worry levels and frequency estimates were unrelated to the source of participants' negative affective state. In accordance with the results of their study, the following hypotheses are offered:

H1: Participants who are exposed to a narrative that describes a tragic outcome due to a specific risk will report higher global worry levels than those exposed to a narrative that describes a positive outcome.

H2: Participants' who are exposed to a narrative that describes a tragic outcome due to a specific risk will report higher global risk frequency estimates than those exposed to a narrative that describes a positive outcome.

\section{Image-based Messaging}

The notion that affect can so substantially alter our judgments, while somewhat troubling to those who wish to properly communicate risk, is evidenced in persuasive tactics found in other domains of communication research. Persuasion research that has informed advertising and marketing strategies takes full advantage of the influence of viewer affect on message receptivity and, more specifically, the impact of imagery on viewer affect. While advertising may seem a world apart from risk communication, their practitioners each fundamentally seek to influence the attitudes of their audiences 
(O'keefe, 2002). While the advertiser appeals to the consumer in the interest of selling a product, risk communicators appeal to their audience in the interest of correcting any misperceptions an audience may have about a given risk. It is therefore important to understand the influence that image presentation has on message receptivity in general, as it is not a tool available only to those who are interested in a financial profit.

Attitudes and judgments. Several advertising effects studies have supported the notion that images have a stronger influence on consumer attitudes and preferences than do text-based messaging strategies (Edell \& Burke, 1987; MacInnis \& Price, 1987; Scott, 1994). What these findings imply is that images have a greater salience for message receivers than do narrative descriptions. For example, Mitchell and Olson's (1981) study on how the content of an advertisement influences viewer attitudes found that the inclusion of images had a significant effect on respondents' beliefs about product attributes, attitudes, and their intentions to purchase the product (p. 327).

More in line with judgments of risk, health communication scholars have noted the influence of image-based messages in promoting or discouraging risky behaviors. In their meta-analysis of health communication messaging, Houts et al. (2006) found that adding images to text-based messages "can increase patient attention, comprehension, recall and adherence" (p. 187). It is unclear, however, if the persuasive power of the image has a similar impact with regard to risk assessments. If imagery is more effective in inducing attitude changes than text-based narratives, whether they are related to the attractiveness of a product or one's propensity to engage in dangerous behaviors, it can 
reasonably be assumed that images should also prove a more powerful influence over risk assessments.

If the ease with which a hazardous image is conjured influences how we judge that hazard, it may well follow that overtly providing that image has a similar effect. Because the hazardous image is provided, exposure to it effectively activates the availability heuristic and, consequently, the affect heuristic. It would then follow, based on Tversky and Johnson's (1983) findings, that participants would estimate the hazard to be more prevalent than those who had not been exposed to the image. Research regarding this question, however, is limited and the effect of image inclusion in this context is not fully understood. Because the current media landscape is heavily reliant on imagery, it is important to gain a better understanding of how such imagery impacts judgments of risk. Therefore, the following research questions are put forth:

RQ1a: Does exposure to an image alongside a tragic narrative result in greater local risk frequency estimates of message receivers than those who only are only exposed to the narrative?

RQ1b: Does exposure to an image alongside a tragic narrative result in greater local worry levels of message receivers than those who only are only exposed to the narrative?

RQ2a: Does exposure to an image alongside a tragic narrative result in greater global risk frequency estimates of message receivers than those who only are only exposed to the narrative? 
RQ2b: Does exposure to an image alongside a tragic narrative result in greater global worry levels of message receivers than those who only are only exposed to the narrative?

It is certainly plausible that participants who are provided with an image will respond similarly to those surveyed by Johnson and Tversky (1983)—-the presence of a tragic image may be no more impactful than a tragic narrative that they find easy to visualize. It may, however, provide a clarity of a hazard that they cannot sufficiently picture in their heads, resulting in a more pronounced impact on their affective response and, as a result, their worry levels and frequency estimates for that particular hazard. 


\section{Chapter Three: Methods}

\section{Overview}

The experimental method employed in this study was designed, like Tversky and Johnson's (1983), to explore the degree to which affect influences judgments of risk. The experimental conditions (detailed in the "Procedure" sub-section below) were designed to elicit an affective response with regard to a specific risk while providing minimal data related to its general prevalence. The affective response of participants could then be recorded across all conditions and compared with participants' frequency estimates regarding a range of potential hazards. Like Tversky and Johnson (1983), this study recorded participants' worry levels and frequency estimates for a range of potentially lethal hazards as a way of measuring their local and global judgments of risk (p. 21). Worry level and frequency estimates served as the dependent variables for the hypotheses and research questions.

The set of risks used in this study is identical to those used in Johnson and Tversky's (1983). They arrived at their set by first surveying an undergraduate population, which identified 36 risks. The authors then narrowed the list to 18 by factoring in those most frequently listed by the students along with those that are actually the most common causes of death.

In order to determine similarity between various risks, Johnson and Tversky (1983) conducted another survey of undergraduate students who were asked to rate the similarity between risks on a 10 point scale. Using an additive tree algorithm (Sattath \& Tversky, 1977) the authors used the survey responses to construct a "tree" of similarity, 
in which the risks " ... appear as terminal nodes of the tree, and the distance between objects is the length of the horizontal part of the path that connects them" (Johnson \& Tversky, 1983, p. 21). The resulting tree is pictured in Figure 1 below.

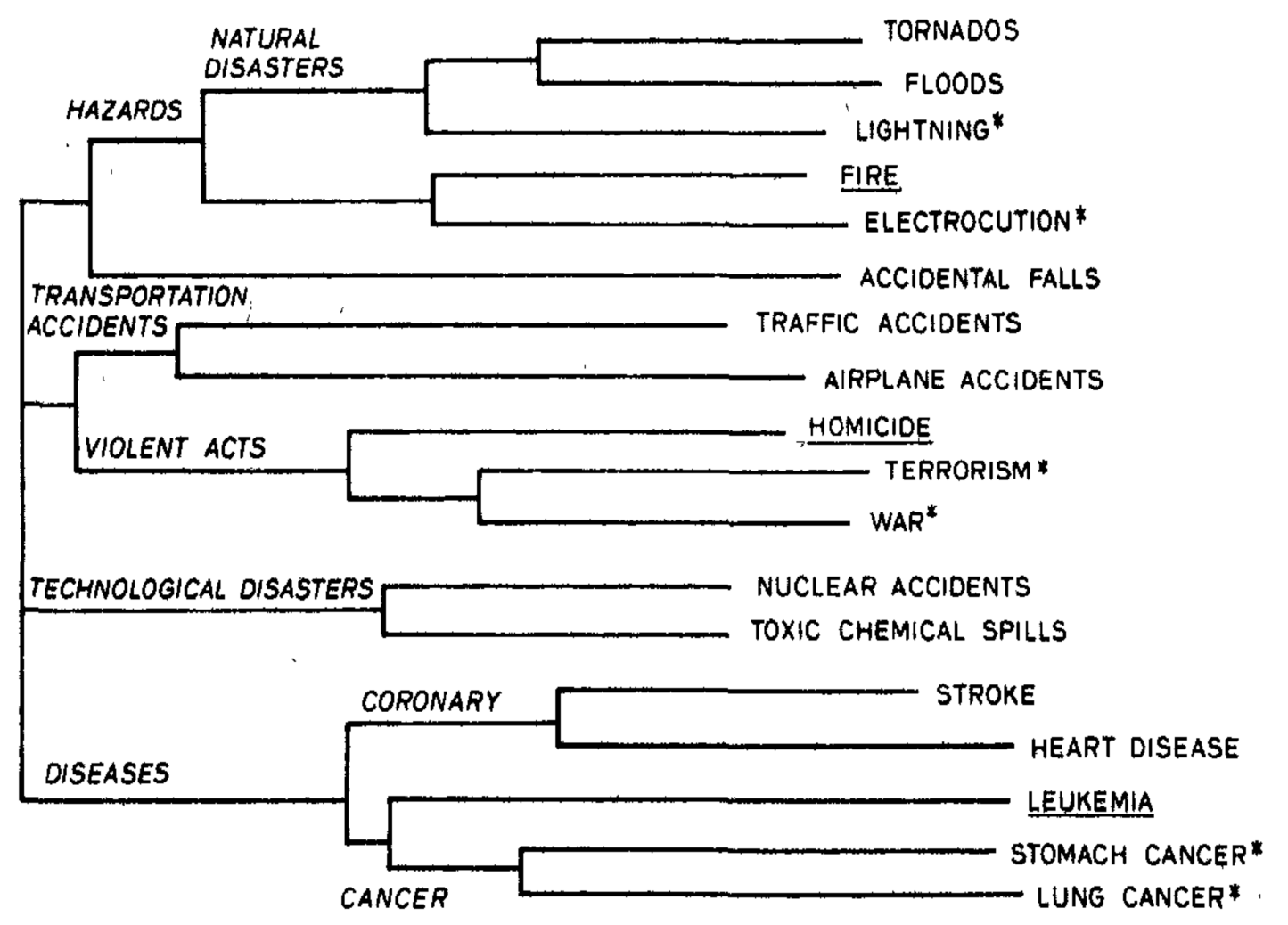

Figure 1. Additive tree representation from Tversky and Johnson (1983, p. 22)

For Johnson and Tversky's (1983) study, the additive tree above served as the basis for determining if reported worry levels and frequency estimates suggested a local or global effect. The same list of hazards was used in this current study. Because the experimental conditions in this study describe death due to a fire, an increase in worry levels and frequency estimates for deaths by fire could be considered an indication of a local effect. Any increase, relative to the control condition, in worry levels or frequency estimates for 
dissimilar hazards - those that fall outside of the "natural disaster" category (tornadoes, floods, lightning, fire, and electrocution)—would suggest a generalized influence and could then be considered an indication of a global effect.

\section{Participants}

Using Amazon Mechanical Turk, an advertisement was placed online to recruit participants for this study. The recruitment took place on March $28^{\text {th }}, 2018$. The advertisement solicited any participants 18 or over, who live in the United States, and have a positive Mechanical Turk rating, which ensured that participants had established themselves as reliable users of the service. Additionally, the population of interest was U.S. residents over the age of 18 and the parameters of the recruitment reflected the target population. After agreeing to an informed consent form that outlined any potential risks associated with participation in the study, as well as confirming their ages to be at least 18 , participants were directed to the online study. All materials presented to participants were approved by Portland State University's Institutional Review Board prior to distribution online.

Of the entire participant pool $(N=254) 18$ participants $(7.1 \%)$ were omitted from the analysis due to incomplete responses $(n=1)$ or a failure to correctly answer the attention check $(n=16)$. A single additional participant was excluded because he or she estimated that over fifty percent of the U.S. population died in 2017. Of the remaining 235 participants, there were 132 males (56.2\%) and 103 females (43.8\%). Participants who reported ethnicity self-identified as White/Caucasian $(n=186,79.1 \%)$, Hispanic or Latino ( $n=16,6.8 \%)$, Black or African American $(n=23,9.8 \%)$, Asian/Pacific Islander 
( $n=16,6.8 \%)$, and "Other" $(n=5,2.1 \%)$. Participant ages ranged from 21 to $69(M=$ $35.87, S D=10.48)$

\section{Procedure}

The study employed a $2 \times 2$ between-subjects factorial design to test the hypotheses and research questions. The independent variables included were story type (positive or tragic) and image inclusion (without image or with image); see table 1.

Table 1

$2 \times 2$ experimental design

Image $(I V)$

\begin{tabular}{|c|c|c|c|}
\hline \multirow{3}{*}{$\begin{array}{c}\text { Story } \\
\text { Type (IV) }\end{array}$} & & Without & With \\
\hline & Positive & $\begin{array}{l}\text { Positive story without } \\
\text { image (Condition one) }\end{array}$ & $\begin{array}{l}\text { Positive story with image } \\
\text { (Condition two) }\end{array}$ \\
\hline & Tragic & $\begin{array}{l}\text { Tragic story without } \\
\text { image (Condition three) }\end{array}$ & $\begin{array}{l}\text { Tragic story with image } \\
\text { (Condition four) }\end{array}$ \\
\hline
\end{tabular}

In accordance with Johnson and Tversky's design (1983, p. 23), the first part of the questionnaire began with the following instructions: "A popular trend in journalism has been the inclusion of personal interest and feature stories. Please carefully read the short newspaper article on the following page and answer the questions that follow." The experimental stimulus was then presented to the participant. 
As a point of reference, the narratives which served as the experimental stimuli in Johnson and Tversky's (1983) original study were described in the following way: All four groups were presented with two brief and mundane items, which were two paragraphs long, modeled after "People in the News" columns in local papers. The three experimental groups each received an additional story about the death of a single person. The experimental stories that describe the fatal events consisted of three paragraphs. The portrayal of the death was detailed, designed to induce anxiety and worry. (p. 23)

The narratives used in the current study were adapted from an actual article in The Oregonian newspaper's online publication, OregonLive.com (Eastman, 2017). It described a local resident who had recently won a remodeled home as a prize giveaway from a popular television program. The positive tone of the article aligned with the "People in the News" type of narrative provided to the control group in the original study (Johnson \& Tversky, 1983).

The positive condition (Condition 1) in this study consisted of a shortened version of the article described above; it appeared underneath a headline that read "Local Man Wins Big." The title of the article was aimed at being both succinct and innocuous so as to avoid any priming effects. For all conditions, the name of the prize winner was changed from Magne Jensen to Steven McInnis. The name change was intended to protect the actual identity of the subject of the piece. The location of the prize home was changed from Knoxville, Tennessee to Ventura, California. The text of the positive article read as follows: 
Good fortune struck Steven McInnis, a local man from Beaverton, Oregon, on Sunday. More than 65 million people had entered HGTV's Urban Oasis Giveaway. And luck hadn't shone much on McInnis in the past. Once, he won a book from a local radio show. But all that changed when his name was drawn and he won the contest's grand prize: A remodeled and furnished bungalow-style house in Southern California, plus $\$ 50,000$ cash.

The home and garden channel's 2017 giveaway was a twist on past pricey drawings. This year, instead of a contemporary home, the winner received a remodeled Craftsman-style house in an upscale neighborhood just outside of Ventura, California. "I figured, what have I got to lose? You never know," McInnis told HGTV. When he first heard he was going to receive a house, he couldn't believe it. "I've never won anything like this in my life," he said. McInnis, his wife, and son plan to move into their new home in April.

The positive condition that included an image (Condition 2) consisted of an identical story and headline alongside an image (see Figure 1) of the home won by the subject of the story. The image was chosen to align with its description—a furnished, bungalow-style home—-and was borrowed from a website of a company that specializes in selling custom home plans for bungalow-style homes ("Bungalow House Plans," n.d.). The negative condition

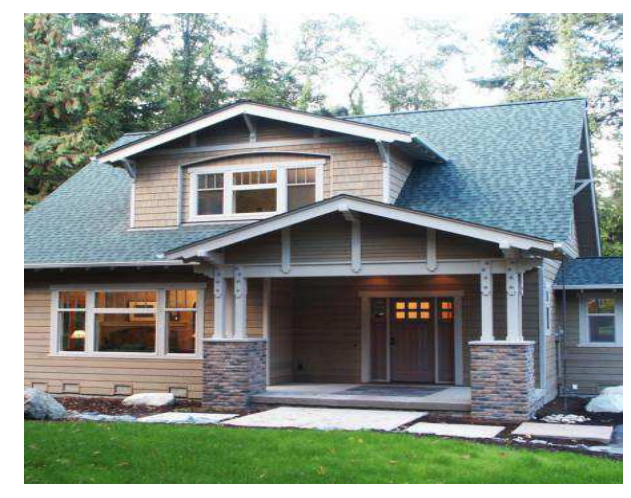

Figure2: Condition 2 image 
(Condition 3) was also adapted from the original The Oregonian article, although it described the subject as having died in a California wildfire while moving into the new home. The location change previously mentioned was included to increase the plausibility of the tragic account. The headline of the story read "Local Man Dies in Wildfire." The title of the article was also aimed at being both succinct and innocuous so as to avoid any priming effects. The text of the tragic article read as follows:

Tragedy struck on Sunday, as Beaverton, Oregon resident Steven McInnis lost his life to the wildfires raging in Southern California. As readers may remember, McInnis was a recent winner of HGTV's Urban Oasis Giveaway. The prize for the contest was a remodeled Craftsman-style house in an upscale neighborhood just outside of Ventura, California, along with $\$ 50,000$ cash. He was in the process of moving into his new home when high winds pushed the fire into his neighborhood overnight, destroying several homes. Late Monday evening, search and rescue officials confirmed that McInnis did not survive the blaze.

Another resident of the neighborhood described the area as looking "like a war zone". "The fire moved so quickly into our neighborhood," she said, "that my son and I were lucky to escape. I don't think that anyone realized just how quickly it could overtake our homes. It's just such a tragedy" McInnis is survived by his wife and their ten year-old son. 
The negative condition that included an image (Condition 4) was structured in much the same way as condition two. The negative story appeared alongside an image of a burning house (Warburg, 2018). The image was borrowed from a Santa Barbara-based news site (see Figure 4). It appeared in an article about pending lawsuits over the Thomas Fire, a California wildfire that burned over 280,000 acres in Southern California from December, 2017 to January, 2018. All conditions were presented in the form of newspaper mock-ups from a fictional newspaper called The Beaverton Times. A fictional

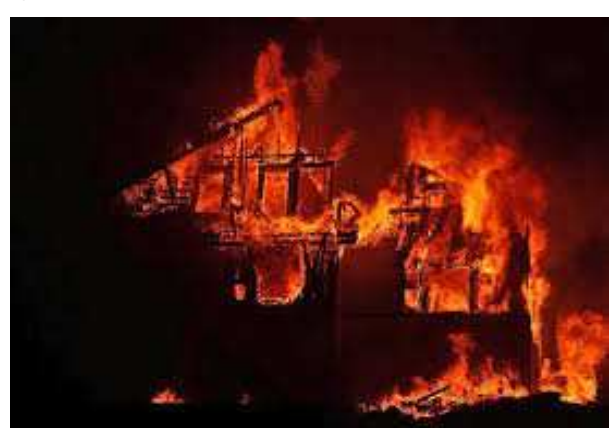

Figure 3: Tragic narrative publication was used in order to avoid activating pre-existing perceptions of source credibility. The masthead of the newspaper was identical for all four conditions. The articles in the positive conditions ( 1 and 2 ) contained 163 words. The articles in the negative conditions ( 3 and 4 ) contained 159 words. The format (font type, image size/position, story position) was matched between conditions.

It should be noted that these conditions were not presented as gain or loss frames; instead, the positive and tragic stories described vastly different outcomes for the subject of the article Participants completed the experiment through Qualtrics, an online survey platform. Each was presented with one of the four conditions. The assignment of the conditions was randomly generated by Qualtrics. The texts and images for all conditions are included in Appendix A.

Participants completed the experiment through Qualtrics, an online survey platform. Each was presented with one of the four conditions. The assignment of the 
conditions was randomly generated by Qualtrics and evenly distributed among the participants.

\section{Measures}

Worry level. In accordance with Johnson and Tversky's (1983) study, worry level was measured using a single item. Participants were asked to rate their level of worry from 1 to 10 for each of the 18 risks (see Figure 1; see Appendix B) used in the original study, with $1=$ not worried at all and $10=$ extremely worried. The order of the risks was automatically randomized through Qualtrics.

Local worry levels were measured by participants' responses to the target risk included in the tragically valenced narrative-fire. Global worry levels were measured by responses to all risks that did not fall into the natural disaster category-accidental falls, traffic accidents, airplane accidents, homicide, terrorism, war, nuclear accidents, toxic chemical spills, stroke, heart disease, leukemia, stomach cancer, and lung cancer (see Figure 1). The mean worry level for these risks combined comprised participants' global worry level.

Frequency estimates. Frequency estimates were also based on the measures used by Johnson and Tversky's (1983) study. Estimates were measured in a similarly simple manner-participants were simply asked to estimate the annual number of fatalities in the U.S. for each of the risks provided. As a way of providing a common anchor to all respondents, participants were first told that approximately 37,000 Americans died in automobile accidents in 2017 (Highway Deaths Lead National Increase in Transportation Fatalities," n.d.). They were then asked to estimate annual fatality totals for the remaining 
17 risks. The order of the risks was automatically randomized through Qualtrics. As with measurements of worry level, proximity to the target risk (fire) was used to determine which risks were categorized as local or global.

Additional measures. All participants were asked after reading the article to rate clarity, style, interest, informativeness, overall quality of writing, and source credibility on a 10 point Likert-type scale. These items served as distractors. Additionally, questions regarding participants' experiences with and attitudes about good fortune were included as distractors to the items that measured participant judgments of lethal events. The questions regarding good fortune served to further disguise the hypotheses and research questions of the study. By disguising the aim of the survey, the distractors mitigate the risk of priming participants and influencing their responses.

Participants were then each asked to answer a single item, 10 point mood question which asked how they would feel if they had read a similar story in a local newspaper. Response options ranged from "Negative, Depressed" to "Positive, Uplifted". This item served as a manipulation check and was identical to the check used in the original study (Johnson \& Tversky, 1983, p.23).

The final set of survey questions recorded demographic data from the participants including, age, gender, and ethnicity.

\section{Analysis}

To ensure valid results, respondents who did not finish the survey or failed the attention check were excluded from the final analysis $(n=19)$. As participants' frequency estimates produced a number of extreme outliers, those estimates were 
winsorized, which is an accepted method of accounting for univariate outliers (Keselman, Algina, Lix, Wilcox, \& Deering, 2008). Winsorizing univariate outliers simply means that "all scores whose $z$ score equivalent is 3.0 or greater are trimmed to whatever score corresponds to a $z$ score of 3.0" (Pelham, 2012, p. 371).

Both hypotheses were analyzed using independent samples $t$ tests and all research questions were analyzed using $2 \times 2$ between-subjects ANOVA testing. Missing cases were excluded pairwise rather than listwise, so that participants' responses were not completely excluded due to an unanswered question. Additionally, because participants' local and global frequency estimates were skewed, chi-square tests were also conducted as sensitivity checks. Significance level for all analysis was set a priori at .05 . 


\section{Chapter Four: Results}

Participant responses to a 10-point mood scale served as a manipulation check.

Those who were exposed to a story with a positive valence $(n=116)$ reported significantly more positive responses $(M=7.7, S D=1.8)$ than did those who were exposed to a tragic story $(n=119, M=3.2, S D=2, t(233)=18, p<.001)$. The manipulation check was therefore successful.

Overall, participants' responses to frequency estimates were highly inconsistent. Across all conditions, global estimate means (the overall mean for all risks outside of the natural disaster category) had a range of just under 470,000 and a standard deviation of over 63,000 . The response range for local frequency estimates (the mean for fire fatalities) was over 180,000, with a standard deviation of over 22,000. Mean worry levels ranged from lows of $2.60(S D=2.35)$ and $2.70(S D=2.58)$ for toxic chemical spills and nuclear accidents, respectively, to highs of $6.32(S D=2.77)$ and $6.47(S D=2.61)$ for heart disease and traffic accidents, respectively.

Hypothesis 1 predicted that participants who were exposed to a narrative that describes a tragic outcome $(n=55)$ due to a specific risk would report higher global worry levels than those exposed to a narrative that describes a positive outcome $(n=54)$. Replicating Johnson and Tversky's (1983) study, neither condition used to test H1 included an image. A two-tailed independent samples $t$ test was conducted on worry levels for all global risks. The results indicated no statistically significant difference between those exposed to a tragic narrative $(M=4.1, S D=2.1)$ and those exposed to a 
positive narrative $(M=4.1, S D=1.9, t(107)=-0.06, p=.95)$. Hypothesis 1 was therefore unsupported.

Similarly, hypothesis 2 predicted that participants exposed to a narrative that describes a tragic outcome due to a specific risk would report higher global frequency estimates than those exposed to a narrative that describes a positive outcome. A twotailed independent samples $t$ test was conducted on mean estimates for all global risks. Hypothesis 2 was unsupported as results indicated no statistically significant difference in global frequency estimates between those who read a tragic story $(M=33,757, S D=$ $67,524)$ and those who read a positive story $(M=27,807, S D=48,332, t(107)=-0.53, p$ $=.60)$.

To analyze the research questions, 2 x 2 between-subjects ANOVA testing was conducted in order to determine if any effects were present according to story valence or image inclusion as well as any interaction effects. Research question 1a examined if the inclusion of an image alongside a tragic narrative would impact participants' local frequency estimates. The results of the ANOVA indicated no significant main effect for image inclusion on participants' local frequency estimates, $F(1 / 231)=2.03, p=.16$. Similarly, no significant effect was observed according to story valence, $F(1 / 231)=0.25$, $p=.62$. Finally, ANOVA testing indicated no significant interaction effect on participants' local frequency estimates, $F(1 / 231)=2.73, p=.10$. In summary, local frequency estimates were not significantly affected by either of the independent variables (see Table 1). 
Research question $1 \mathrm{~b}$ examined if the inclusion of an image alongside a tragic narrative would impact participants' local worry levels. The results of ANOVA testing indicated no significant main effect for image inclusion on participants' local worry levels, $F(1 / 231)=0.00, p=.99$. Similarly, no significant effect was observed according to story valence, $F(1 / 231)=0.28, p=.60$. Finally, ANOVA testing indicated no significant interaction effect on participants' local frequency estimates, $F(1 / 231)=0.20$, $p=.66$. Just as with local frequency estimates, participants' local worry levels were not significantly impacted by either of the independent variables.

Table 2

Local Frequency Estimates

\begin{tabular}{|c|c|c|c|}
\hline Story Valence & $N$ & $M$ & $S D$ \\
\hline \multicolumn{4}{|l|}{ Positive } \\
\hline Without Image & 54 & 8,202 & 24,688 \\
\hline With Image & $\underline{62}$ & $\underline{8,860}$ & 15,768 \\
\hline Total & 116 & 7,158 & 28,698 \\
\hline \multicolumn{4}{|l|}{ Tragic } \\
\hline Without Image & 55 & 14,470 & 32,080 \\
\hline$\underline{\text { With Image }}$ & $\underline{64}$ & $\underline{5,509}$ & $\underline{13,636}$ \\
\hline Total & 119 & 9,650 & 24,297 \\
\hline
\end{tabular}

Research questions $2 \mathrm{a}$ and $2 \mathrm{~b}$ were concerned with global frequency estimates and worry levels and, like RQ1a and RQ1b, whether image inclusion would impact participant responses. For RQ2a, ANOVA testing indicated no significant effect for 
image inclusion $(F(1 / 231)=1.32, p=.25)$ or story valence $(F(1 / 231)=0.02, p=.90)$ on global frequency estimates. Additionally, no significant interaction effects were revealed, $F(1 / 231)=0.73, p=.40$. Similar to local frequency estimates, participants' global frequency estimates were not significantly impacted by either of the independent variables (see Table 2).

Research question $2 \mathrm{~b}$ examined if image inclusion would impact participants' global worry levels. ANOVA testing indicated no significant effect for image inclusion, $F(1 / 231)=3.24, p=.07$. Similarly, no significant effect was revealed for story valence on global worry levels, $F(1 / 231)=0.13, p=.72$. Finally, ANOVA testing revealed no interaction effects on global worry levels, $F(1 / 231)=0.20, p=.66$. As with all research questions posed, neither of the independent variables significantly impacted participants' global worry levels.

Because both local and global frequency estimates were skewed, estimates were also broken into deciles to allow for non-parametric testing. Analysis using chi-square testing revealed no significant effect for story valence $\left(\chi^{2}(9)=2.2, p=.99\right)$ or image inclusion $\left(\chi^{2}(9)=8.4, p=.50\right)$ on participants' global frequency estimates. Similarly, chisquare testing revealed no significant effect for story valence $\left(\chi^{2}(9)=4.3, p=.89\right)$ or image inclusion $\left(\chi^{2}(9)=4.3, p=.47\right)$ on participants' local frequency estimates.

\section{Post-hoc Analysis}

In order to examine the relationship between worry levels and frequency estimates, correlation testing was run on participant responses for each individual risk. 
Table 3

Global Frequency Estimates

\begin{tabular}{lccc}
\hline Story Valence & $N$ & $M$ & $S D$ \\
\hline Positive & & & \\
Without Image & 54 & 27,807 & 48,332 \\
$\frac{\text { With }}{\underline{\text { Image }}}$ & $\underline{62}$ & $\underline{44,441}$ & $\underline{69,095}$ \\
$\quad$ Total & 116 & 36,698 & 60,650 \\
Tragic & & 33,757 & \\
Without Image & 55 & $\underline{35,878}$ & 67,524 \\
$\quad \underline{\text { With }}$ & $\underline{64}$ & 35,078 & 63,436 \\
$\quad \underline{\text { Total }}$ & 119 & & 66,286 \\
\hline
\end{tabular}

The results revealed significant positive correlations between worry levels and frequency estimates for all but three of the risks presented—heart disease, lung cancer, and homicide.

When comparing all four conditions, only the tragic narrative which included an image revealed a significant correlation between local frequency estimates and worry levels, $r_{\mathrm{s}}=0.29, n=64, p=.02$. When comparing tragic and positive narrative valence, only the tragic stories revealed a significant correlation, $r_{\mathrm{s}}=0.23, n=119, p=.01$. When comparing image inclusion and image exclusion, only those narratives which included an image revealed a significant correlation between local frequency estimates and local worry levels, $r_{\mathrm{s}}=0.24, n=126, p=.01$. 
Table 4

Correlations between frequency estimates and worry levels

\begin{tabular}{|c|c|c|}
\hline Risk & $r_{\mathrm{s}}$ & $p$ \\
\hline Floods & .29 & $<.001 * *$ \\
\hline Stomach Cancer & .16 & $.01 *$ \\
\hline Tornadoes & .24 & $<.001 * *$ \\
\hline Heart Disease & .02 & .75 \\
\hline Homicide & .01 & .91 \\
\hline Nuclear Accidents & .31 & $<.001 * *$ \\
\hline Terrorism & .35 & $<.001 * *$ \\
\hline Leukemia & .15 & $.03 *$ \\
\hline Lightning Strikes & .30 & $<.001 * *$ \\
\hline Lung Cancer & .06 & .32 \\
\hline Accidental Falls & .15 & $.02 *$ \\
\hline Stroke & .14 & $.03 *$ \\
\hline Airplane Accidents & .26 & $<.001 * *$ \\
\hline Electrocution & .18 & $<.01 * *$ \\
\hline War & .42 & $<.001 * *$ \\
\hline Toxic Chemical Spills & .39 & $<.001 * *$ \\
\hline
\end{tabular}




\section{Chapter Five: Discussion}

Although this study revealed no statistically significant findings with regard to the hypotheses and research questions, there are inferences that can potentially be drawn from these results. Hypotheses 1 and 2 predicted that participants exposed to a tragic narrative would report higher global worry levels and frequency estimates, respectively, than those exposed to a positively valenced narrative. Neither hypothesis was supported by this study's findings. The research questions addressed the potential for an image placed alongside a narrative to influence local and global worry levels and frequency estimates. The results indicated that participant responses were not influenced by the presence of an image. In short, the results of this study suggest that neither the valence of a narrative nor the presence of an accompanying image has an impact on readers' judgments of a wide variety of lethal risks.

This section will highlight a few factors that may have played a part in producing the results of this study—generational shifts in how mediated messages are processed, the difficulty of making risk estimates, and finally, the potential overstatement of how affect impacts judgments of risk. Additionally, the relationship between worry levels and risk estimates will be addressed, with special attention paid to the influence of perceived control of risk.

\section{The Trouble with Risk Estimates}

One surprising result of this study's findings is the wide range of responses with regard to frequency estimates. Because global estimates were calculations of the overall mean for twelve risks, it is perhaps reasonable that the range estimates was so large. 
However, analysis of local frequency estimates (mean estimates for a single risk-fire) also revealed a sizable range of responses.

Though surprising, the vast range of responses observed in this study does support previous research, which has noted the difficulty that many people have with making predictive judgments of risk (Adelswärd, \& Sachs, 1996; Lipkus, Samsa, \& Rimer, 2001). Even when provided with an anchor-the number of annual traffic fatalitiesrespondents' frequency estimates varied wildly. These results make those found by Johnson and Tversky (1983) all the more surprising. Observing statistical significance in a set of responses so shockingly erratic was unexpected.

\section{Generational Shifts}

Because Johnson and Tversky's (1983) original study was conducted 35 years ago, participants now may have a greater familiarity with mediated narratives of tragedy than they did then in the early 1980s. One might assume that the average media consumer is now more desensitized to emotional narrative or images than they once were. This, however, does not account for the results which indicated the valance of the narrative did influence participants' responses to the 10-point mood scale, which served as the manipulation check. The wording of the manipulation check may account for how participants responded - "How would you feel if you had read this story in your local newspaper or saw it on Facebook?" The word "would" may have prompted participants to report not how they did feel after exposure to the stimulus but how they imagine they would feel.

\section{The Influence of Affect}


One factor that may supersede a person's particular affective state is their general emotional disposition. If a particular respondent is of a generally optimistic disposition, for example, the impact of their affective response to a tragic narrative may be blunted. Butler and Matthews (1983) found that both anxious and depressed individuals overestimated risk when compared with matched control subjects (p. 58). Others studies have found that valence may be too broad to be considered the causal agent in how people estimate risk. For example, Lerner and Keltner (2000) found that inducing two emotions that can both be described as negative- fear and anger-produced different results from one another. Fearful individuals reported significantly higher risk assessments than did angry individuals (p. 484). Lerner and Keltner (2000) attributed this finding to each emotion's relationship to certainty and control. Angry participants, they found, perceived greater certainty and control over their environment and fearful participants perceived less of each (p. 485). If fear and anger are better predictors of how emotion influences judgments of risk, then simply measuring positive or negative affect may be insufficient.

\section{Risk and Judgments of Control}

Varying the control that participants' might have over the events described in this study's stimuli may be particularly fruitful in investigating the role that control has in how we judge risk. The narratives presented, regardless of condition, implied a lack of control over the outcomes described. The positively valenced narratives described someone who was struck by good fortune-winning a prize from a random drawing. The 
tragically valenced narratives described someone who was struck by bad fortunetrapped by a rapidly-approaching wildfire.

The simplest inference that one could draw from these results is that affective states are not sufficient to significantly alter people's risk frequency estimates and worry levels. That assertion, however, implies flawed or unsatisfactory conclusions suggested by much of the research on this subject. No single study is sufficient to rebut decades of research. This study, however, does potentially offer some additional insight into the relative influence of affective states on judgments of risk.

Post hoc analysis demonstrated one particular result that warrants examination. While participants' estimates were quite erratic, their worry levels tended to correlate with their estimates for each risk. There were, however, three exceptions. Worry levels and frequency estimates were not correlated with regard to lung cancer, heart disease, and homicide. These risks are particularly noteworthy as they are each related to control.

One factor that was not explicitly measured in this study is that of an individual's ability to control a given risk. Many of the risks that participants were asked to rate were disasters or accidents that could easily be judged as uncontrollable. However, lung cancer, heart disease, and homicide may have been perceived as controllable, which could account for these non-correlated results. For example, a participant might recognize the high rate of lung cancer in America but the participant is a non-smoker. This might lead to a high estimate and a low worry level. Participants may understand lung cancer to be a disease that is best attributed to lifestyle choices (Riles, Sangalang, Hurley, \& Tewksbury, 2015). The same can be said for heart disease — it is a health issue that 
primarily affects the middle-aged and older and is also perceived to be controllable through diet and exercise. Finally, homicide is a lethal risk that is certainly sensational and therefore receives much attention from news sources. That, however, does not necessarily translate into high levels of worry for participants. They may very well think that the homicide rate is high but only in certain cities or communities. "It is dangerous in those places," they might think, "but not here." In this case their perceived control is geographically based, whereas judgments of the other two risks were based primarily on lifestyle.

\section{Limitations and Directions for Future Research}

This study was not without its limitations. First, the participant pool for the study was drawn from Mechanical Turk, whose worker pool tends to skew younger, slightly better educated, and more likely Caucasian than the general population of the United States (Sheehan, 2018, p. 4). Indeed, the demographic composition in this study potentially suffers from the "white male effect", which suggests that white males feel less vulnerable to risk and they therefore underestimate risk in general (Finucane, Slovic, Mertz, Flynn, \& Satterfield, 2000). A truly generalized U.S. population may be more revealing in terms of how we make judgments of risk. Second, this study did not include participants' personal experience with any of the risks. If one is to examine both the availability and affect heuristics, factoring in personal experience would better illuminate the results. After all, availability and affect are largely dependent upon the "imprint" that an event or class of events has in the mind of a given participant. Exposing a participant to a narrative describing a tragic incident might well elicit different responses from those 
who have personal experience with a similar tragedy than with one who has not.

Additionally, future research into this subject might get better results if the accuracy of participants' frequency estimates are somehow incentivized. The massive range of estimates could potentially be attenuated if participants were truly trying to estimate correctly. If the same range of responses were found, even with the inclusion of accuracy incentives, the results from this study could be more solidly supported as truly reflective of participants' best-faith efforts. Such an experiment could be run in a laboratory setting to ensure that participants are not tempted to retrieve the actual numbers from other sources.

Finally, the current media landscape is heavily video-based and researchers would be wise to integrate video elements into their experimental designs. A still photo of, in this case, a house on fire may not sufficiently elicit a strong emotional reaction. Updating the stimuli to fit the current media environment would be a well-advised strategy for arriving at results with greater external validity.

\section{Conclusion}

The manner by which humans make judgments about risk is still somewhat murky. Research has indicated that cognitive heuristics certainly play a central role, although to what extent and to what effect is not entirely clear. Johnson and Tversky's (1983) study found that a person's affect toward a specific risk influences not only their judgment of that risk but a wide variety of separate, unrelated risks. This study found that valence had no effect on such judgments. 
Additionally, the inclusion of an image in messages regarding lethal risk had no effect on how participants judged risk in general. Although it seems to make logical sense that providing a tragic image would effectively activate both the affect and availability heuristics, this study showed no evidence of such activation. Regardless of the valence of the narrative presented, inclusion of an accompanying image did not influence participants' worry or frequency estimates either locally or globally.

There is a substantial body of literature that suggests both availability and affect are significant factors in how we judge risk, although positive and negative affect are both broad classifications of one's emotional state. In the same regard, a person's sense of control or certainty likely plays a part in how on assesses risk. Accounting for each variable in making such determinations is clearly a challenge. A greater understanding of how we process risk, though, is of real importance. An individual, a group, or even a society that badly misjudges risk is prone to over or undercompensate when they try to address a given risk. If we, collectively, have a more well-calibrated understanding of the risks to which we are exposed, we may then be more likely to take reasonable steps to mitigate pervasive risks, and perhaps less likely to overinflate our concern about sensationalized, yet uncommon risks. 


\section{References}

Adelswärd, V., \& Sachs, L. (1996). The meaning of 6.8: numeracy and normality in health information talks. Social Science \& Medicine, 43(8), 1179-1187.

Arrow, K. J. (1982). Risk perception in psychology and economics. Economic Inquiry, 20(1), 1-9.

Baron, J., Hershey, J. C., \& Kunreuther, H. (2000). Determinants of priority for risk reduction: the role of worry. Risk Analysis, 20(4), 413-428.

Black, W. C., Nease Jr, R. F., \& Tosteson, A. N. (1995). Perceptions of breast cancer risk and screening effectiveness in women younger than 50 years of age. JNCI: Journal of the National Cancer Institute, 87(10), 720-731.

Borkovec, T. D., Ray, W. J., \& Stober, J. (1998). Worry: A cognitive phenomenon intimately linked to affective, physiological, and interpersonal behavioral processes. Cognitive Therapy and Research, 22(6), 561-576.

Bungalow House Plans. (n.d.). Retrieved from https://thebungalowcompany.com/

Butler, G., \& Mathews, A. (1983). Cognitive processes in anxiety. Advances in behaviour research and therapy, 5(1), 51-62.

Coleman, C.-L. (1993). The influence of mass media and interpersonal communication on societal and personal risk judgments. Communication Research, 20(4), 611628.

Dunwoody, S., \& Neuwirth, K. (1991). Coming to terms with the impact of communication on scientific and technological risk judgments. Risky business: Communicating issues of science, risk, and public policy, 11-30. 
Eastman, J. (2017, December 27). Beaverton retiree wins HGTV's remodeled bungalow (before, after photos). Retrieved from https://www.oregonlive.com/hg/index.ssf/2017/12/hgtv_bungalow_oregon_winne r.html

Edell, J. A., \& Burke, M. C. (1987). The power of feelings in understanding advertising effects. Journal of Consumer Research, 14(3), 421-433.

Finucane, M. L., Alhakami, A., Slovic, P., \& Johnson, S. M. (2000). The affect heuristic in judgments of risks and benefits. Journal of Behavioral Decision Making, 13(1), 1.

Finucane, M. L., Slovic, P., Mertz, C. K., Flynn, J., \& Satterfield, T. A. (2000). Gender, race, and perceived risk: The'white male'effect. Health, risk \& society, 2(2), 159172.

Firestone, C., \& Scholl, B. J. (2015). When do ratings implicate perception versus judgment? The "overgeneralization test" for top-down effects. Visual Cognition, 23(9-10), 1217-1226.

Fischhoff, B., Slovic, P., Lichtenstein, S., Read, S., \& Combs, B. (1978). How safe is safe enough? A psychometric study of attitudes towards technological risks and benefits. Policy Sciences, 9(2), 127-152.

Fishburn, P. C. (1970). Utility theory for decision making. Research Analysis Corp Mclean, VA.

Folkes, V. S. (1988). The availability heuristic and perceived risk. Journal of Consumer Research, 15(1), 13-23. 
Freeston, M. H., Rhéaume, J., Letarte, H., Dugas, M. J., \& Ladouceur, R. (1994). Why do people worry?. Personality and individual differences, 17(6), 791-802.

Gramlich, J. (2016, November 16). Voters' perceptions of crime continue to conflict with reality. http://www.pewresearch.org/fact-tank/2016/11/16/voters-perceptions-ofcrime-continue-to-conflict-with-reality/

Harrington, N. G., \& Kerr, A. M. (2017). Rethinking risk: Prospect theory application in health message framing research. Health Communication, 32(2), 131-141.

Highway Deaths Lead National Increase in Transportation Fatalities. (n.d.). Retrieved from https://www.ntsb.gov/news/press-releases/Pages/PR20171121.aspx

Houts, P. S., Doak, C. C., Doak, L. G., \& Loscalzo, M. J. (2006). The role of pictures in improving health communication: a review of research on attention, comprehension, recall, and adherence. Patient Education and Counseling, 61(2), 173-190.

Johnson, E. J., \& Tversky, A. (1983). Affect, generalization, and the perception of risk. Journal of Personality and Social Psychology, 45(1), 20.

Kahneman, D. (2011). Thinking, fast and slow. New York, NY: Farrar, Strauss and Giroux.

Keller, C., Siegrist, M., \& Gutscher, H. (2006). The role of the affect and availability heuristics in risk communication. Risk Analysis, 26(3), 631-639.

Keselman, H. J., Algina, J., Lix, L. M., Wilcox, R. R., \& Deering, K. N. (2008). A generally robust approach for testing hypotheses and setting confidence intervals 
for effect sizes. Psychological Methods, 13(2), 110-129. doi:10.1037/1082989X.13.2.110

Kim, D. J., Ferrin, D. L., \& Rao, H. R. (2008). A trust-based consumer decision-making model in electronic commerce: The role of trust, perceived risk, and their antecedents. Decision Support Systems, 44(2), 544-564.

Lerner, J. S., \& Keltner, D. (2000). Beyond valence: Toward a model of emotion-specific influences on judgement and choice. Cognition \& emotion, 14(4), 473-493.

Lichtenstein, S., Slovic, P., Fischhoff, B., Layman, M., \& Combs, B. (1978). Judged frequency of lethal events. Journal of Experimental Psychology: Human Learning and Memory, 4(6), 551.

Lipkus, I. M., Samsa, G., \& Rimer, B. K. (2001). General performance on a numeracy scale among highly educated samples. Medical decision making, 21(1), 37-44.

Lopes, L. L. (1987). Between hope and fear: The psychology of risk. Advances in Experimental Social Psychology, 20, 255-295.

Lu, H.-P., Hsu, C.-L., \& Hsu, H.-Y. (2005). An empirical study of the effect of perceived risk upon intention to use online applications. Information Management \& Computer Security, 13(2), 106-120.

MacInnis, D. J., \& Price, L. L. (1987). The role of imagery in information processing: Review and extensions. Journal of Consumer Research, 13(4), 473-491.

Massumi, B. (1995). The autonomy of affect. Cultural critique, (31), 83-109. 
Mitchell, A. A., \& Olson, J. C. (1981). Are product attribute beliefs the only mediator of advertising effects on brand attitude? Journal of Marketing Research, 18(3), 318332.

Mongin, P. (1997). Expected utility theory. Handbook of Economic Methodology, 342350 .

Moser, D. V. (1989). The effects of output interference, availability, and accounting information on investors' predictive judgments. Accounting Review, 433-448.

Mossin, J. (1968). Taxation and risk-taking: an expected utility approach. Economica, 35(137), 74-82.

O'keefe, D. J. (2002). Persuasion: Theory and research (Vol. 2). Thousand Oaks, CA: Sage.

Palenchar, M. J., \& Heath, R. L. (2007). Strategic risk communication: Adding value to society. Public Relations Review, 33(2), 120-129.

Pelham, B. W. (2012). Intermediate statistics: A conceptual course. Thousand Oaks, CA: Sage.

Peters, E. (2012). Beyond comprehension: The role of numeracy in judgments and decisions. Current Directions in Psychological Science, 21(1), 31-35.

Peters, E., Slovic, P., Västfjäll, D., \& Mertz, C. K. (2008). Intuitive numbers guide decisions. Judgment and Decision Making, 3(8), 619-635.

Pratt, J. W. (1964). Risk aversion in the small and in the large. Econometrica: Journal of the Econometric Society, 122-136. 
Riles, J. M., Sangalang, A., Hurley, R. J., \& Tewksbury, D. (2015). Framing cancer for online news: Implications for popular perceptions of cancer. Journal of Communication, 65(6), 1018-1040.

Rottenstreich, Y., \& Hsee, C. K. (2001). Money, kisses, and electric shocks: On the affective psychology of risk. Psychological Science, 12(3), 185-190.

Sattath, S., \& Tversky, A. (1977). Additive similarity trees. Psychometrika, 42(3), 319345.

Schwarz, N., Bless, H., Strack, F., Klumpp, G., Rittenauer-Schatka, H., \& Simons, A. (1991). Ease of retrieval as information: Another look at the availability heuristic. Journal of Personality and Social Psychology, 61(2), 195.

Schwarz, N., \& Clore, G. L. (2007). Feelings and phenomenal experiences. In A. Kruglanski \& E. T. Higgins (Eds.), Social psychology. Handbook of basic principles (2nd ed.; pp. 385-407). New York: Guilford.

Scott, L. M. (1994). Images in advertising: The need for a theory of visual rhetoric. Journal of Consumer Research, 21(2), 252-273.

Sheehan, K. B. (2018). Crowdsourcing research: Data collection with Amazon's Mechanical Turk. Communication Monographs, 85(1), 140-156.

Sherman, S. J., Cialdini, R. B., Schwartzman, D. F., \& Reynolds, K. D. (1985). Imagining can heighten or lower the perceived likelihood of contracting a disease: The mediating effect of ease of imagery. Personality and Social Psychology Bulletin, 11(1), 118-127. 
Simon, H. A. (1992). What is an "Explanation" of Behavior? Psychological Science, 3(3), 150-161. doi:10.1111/j.1467-9280.1992.tb00017.x

Slovic, P. (1993). Perceived risk, trust, and democracy. Risk Analysis, 13(6), 675-682.

Slovic, P. (2016). The perception of risk. London: Routledge.

Slovic, P., Finucane, M. L., Peters, E., \& MacGregor, D. G. (2004). Risk as analysis and risk as feelings: Some thoughts about affect, reason, risk, and rationality. Risk Analysis, 24(2), 311-322.

Slovic, P., Fischhoff, B., \& Lichtenstein, S. (1980). Facts and fears: Understanding perceived risk. Societal Risk Assessment: How Safe Is Safe Enough, 4, 181-214.

Slovic, P., Fischhoff, B., \& Lichtenstein, S. (1981). Facts and fears: societal perception of risk. ACR North American Advances.

Slovic, P., \& Peters, E. (2006). Risk perception and affect. Current directions in psychological science, 15(6), 322-325.

Slovic, P., Peters, E., Finucane, M. L., \& MacGregor, D. G. (2005). Affect, risk, and decision making. Health Psychology, 24(4S), S35.

Starr, C. (1969). Social benefit versus technological risk. Science, 1232-1238.

Tversky, A., \& Kahneman, D. (1973). Availability: A heuristic for judging frequency and probability. Cognitive Psychology, 5(2), 207-232.

Tversky, A., \& Kahneman, D. (1975). Judgment under uncertainty: Heuristics and biases (pp. 141-162). Springer.

Warburg, Z. (2018, January 5). 3 Lawsuits Blame Southern California Edison for Thomas Fire. Retrieved from 
https://www.noozhawk.com/article/3_lawsuits_blame_southern_california_edison _for_thomas_fire

Wray, R. J., Kreuter, M. W., Jacobsen, H., Clements, B., \& Evans, R. G. (2004). Theoretical perspectives on public communication preparedness for terrorist attacks. Family \& Community Health, 27(3), 232-241.

Zajonc, R. B. (1980). Feeling and thinking: Preferences need no inferences. American Psychologist, 35(2), 151-175. doi:10.1037/0003-066x.35.2.151 


\section{Appendix A - Experimental Stimuli}

All conditions begin with the following statement:

"A popular trend in journalism has been the inclusion of personal interest and feature stories. Please carefully read the short newspaper article on the following page and answer the questions that follow."

\section{$\underline{\text { Positive Condition }}$}

\section{The Beaverton Daily \\ Local Man Wins Big}

Courtesy of the Associated Press

Good fortune struck Steven McInnis, a local man from Beaverton, Oregon, on Sunday. More than 65 million people had entered HGTV's Urban Oasis Giveaway. And luck hadn't shone much on Jensen in the past. Once, he won a book from a local radio show. But all that changed when his name was drawn and he won the contest's grand prize: A remodeled and furnished bungalowstyle house in Southern California, plus $\$ 50,000$ cash.

The home and garden channel's 2017 giveaway was a twist on past pricey drawings. This year, instead of a contemporary home, the winner received a remodeled Craftsman-style house in an upscale neighborhood just outside of Ventura, California. "I figured, what have I got to lose? You never know," McInnis told HGTV. When he first heard he was going to receive a house, he couldn't believe it. "I've never won anything like this in my life," he said. McInnis, his wife, and son plan to move into their new home in April. 


\section{$\underline{\text { Positive Condition with Image }}$}

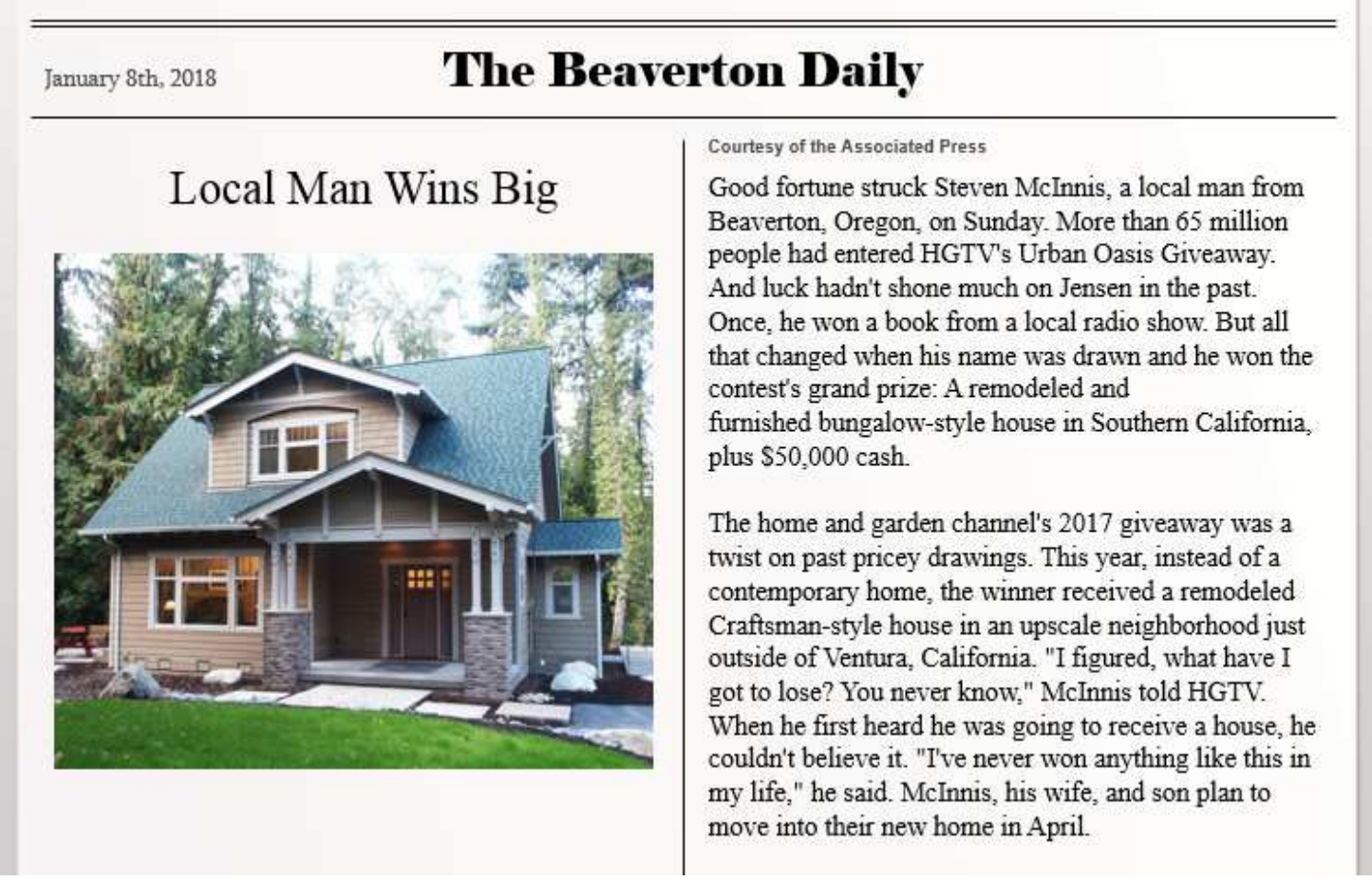


$\underline{\text { Tragic Condition }}$

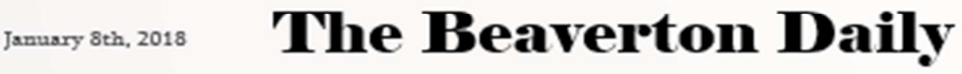 \\ Local Man Dies in Wildfire}

Courtesy of the Associated Press

Tragedy struck on Sunday, as Beaverton, Oregon resident Steven McInnis lost his life to the wildfires raging in Southern California. As readers may remember, McInnis was a recent winner of HGTV's Urban Oasis Giveaway. The prize for the contest was a remodeled Craftsman-style house in an upscale neighborhood just outside of Ventura, California, along with $\$ 50,000$ cash. He was in the process of moving into his new home when high winds pushed the fire into his neighborhood overnight, destroying several homes. Late Monday evening, search and rescue officials confirmed that McInnis did not survive the blaze.

Another resident of the neighborhood described the area as looking, "like a war zone." "The fire moved so quickly into our neighborhood," she said, "that my son and I were lucky to escape. I don't think that anyone realized just how quickly it could overtake our homes. It's just such a tragedy." McInnis is survived by his wife and their ten year-old son. 
$\underline{\text { Tragic Condition with Image }}$

January 8 th, 2018 The Beaverton Daily

\section{Local Man Dies in Wildfire}

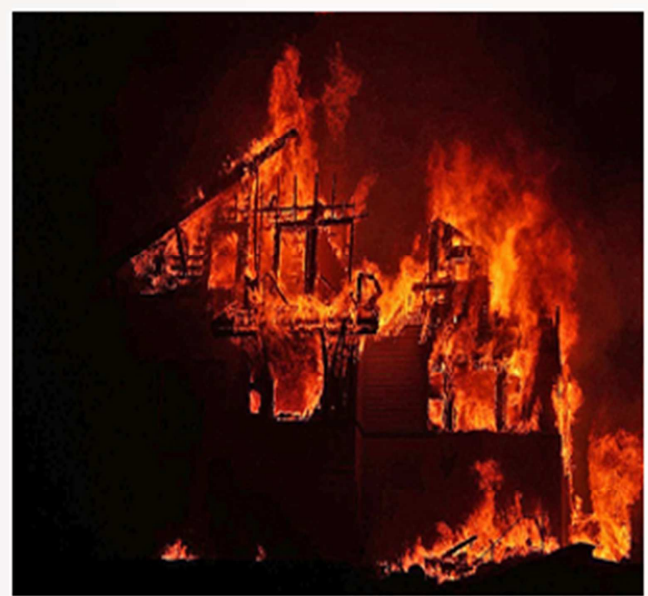

Courtesy of the Associated Press

Tragedy struck on Sunday, as Beaverton, Oregon resident Steven McInnis lost his life to the wildfires raging in Southern California. As readers may remember, McInnis was a recent winner of HGTV's Urban Oasis Giveaway. The prize for the contest was a remodeled Craftsman-style house in an upscale neighborhood just outside of Ventura, California, along with $\$ 50,000$ cash. He was in the process of moving into his new home when high winds pushed the fire into his neighborhood overnight, destroying several homes. Late Monday evening, search and rescue officials confirmed that McInnis did not survive the blaze.

Another resident of the neighborhood described the area as looking, "like a war zone." "The fire moved so quickly into our neighborhood," she said, "that my son and I were lucky to escape. I don't think that anyone realized just how quickly it could overtake our homes. It's just such a tragedy." McInnis is survived by his wife and their ten year-old son. 
54

Appendix B - Survey Instrument

Q7 On a scale from 1 to 10, please rate the article you have just read according to the elements listed below.

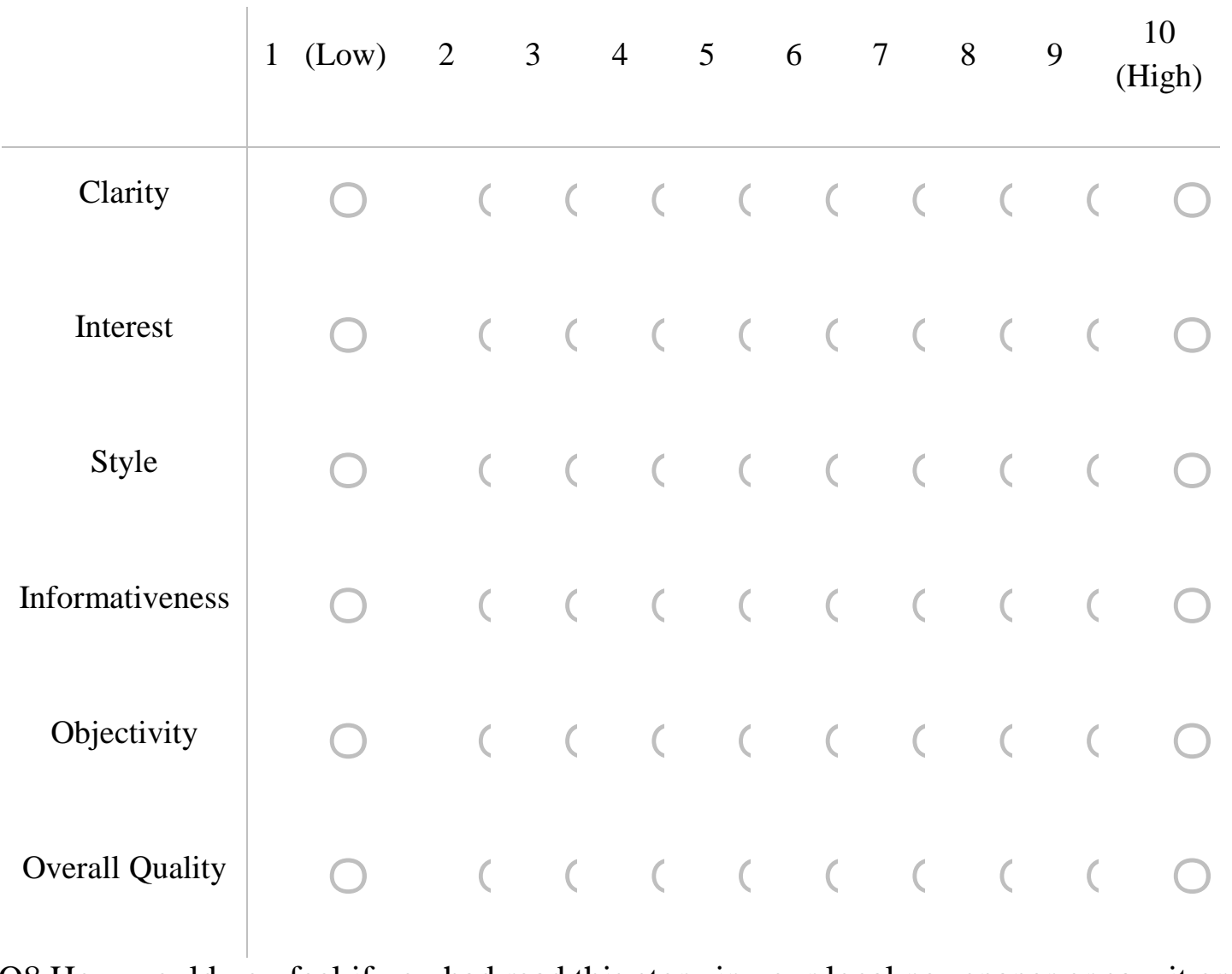

Q8 How would you feel if you had read this story in your local newspaper or saw it on Facebook?

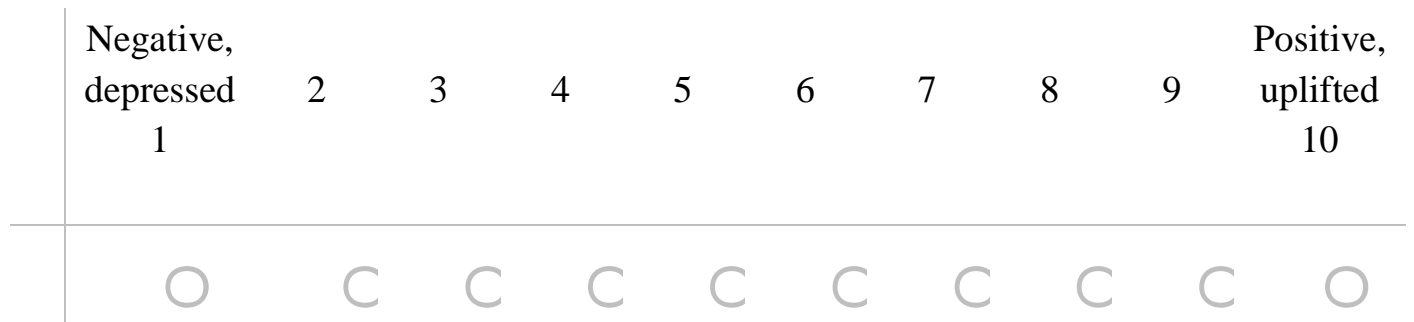


Q13 Please estimate the number of people in the United States that die each year from the following causes. For your reference, traffic accidents accounted for about 37,000 deaths in the U.S. in 2017.

Leukemia

Floods

Stomach Cancer

Tornadoes

Heart Disease

Homicide

Nuclear Accidents

Terrorism

Lightning Strikes

Lung Cancer

Accidental Falls

Stroke

Airplane Accidents

Electrocution

Fire 
56

War

Toxic Chemical Spills

Q14 For each potential hazard listed below, please indicate your general level of worry on a scale from 1 (Not worried at all) to 10 (Extremely worried).

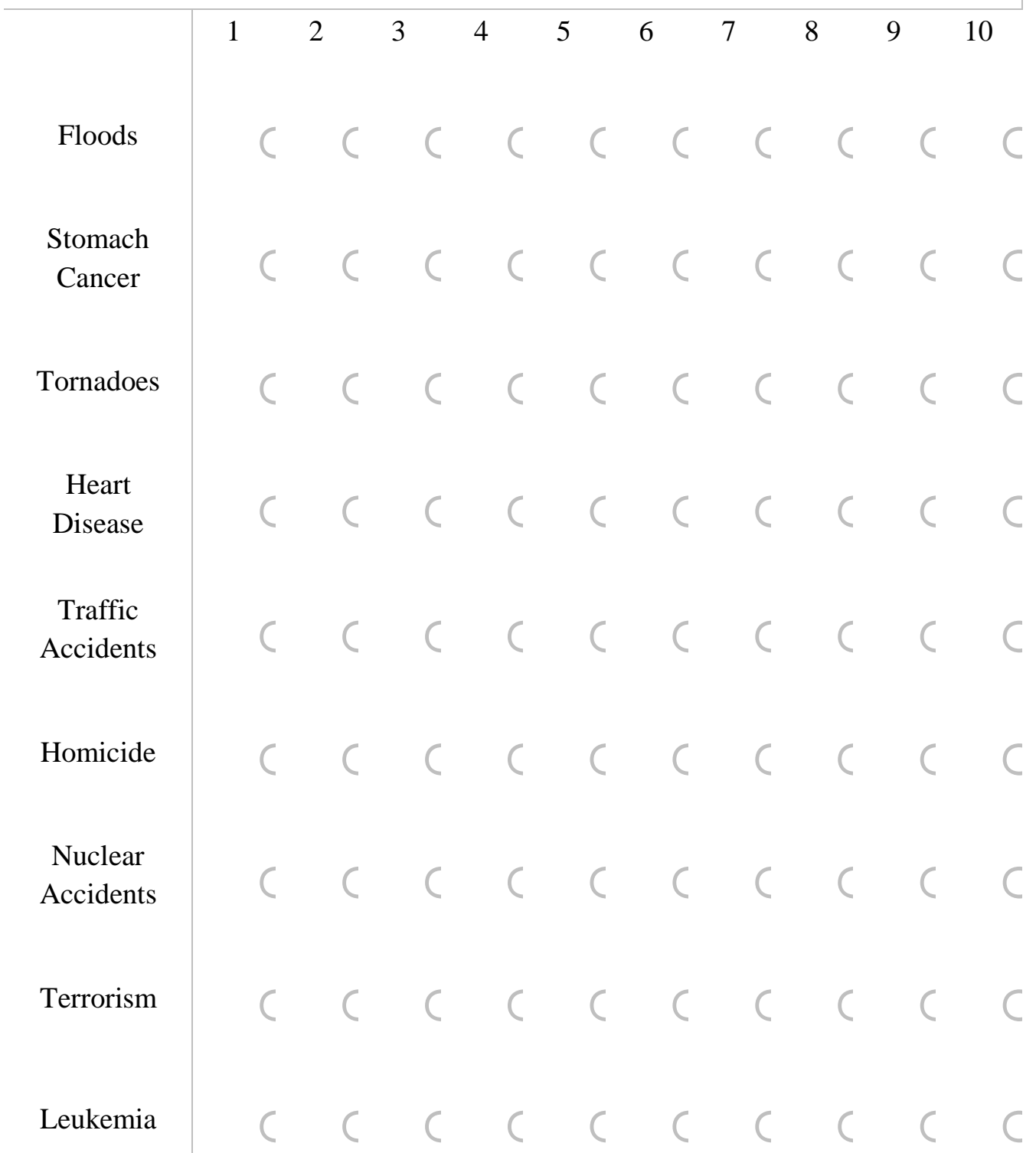


57

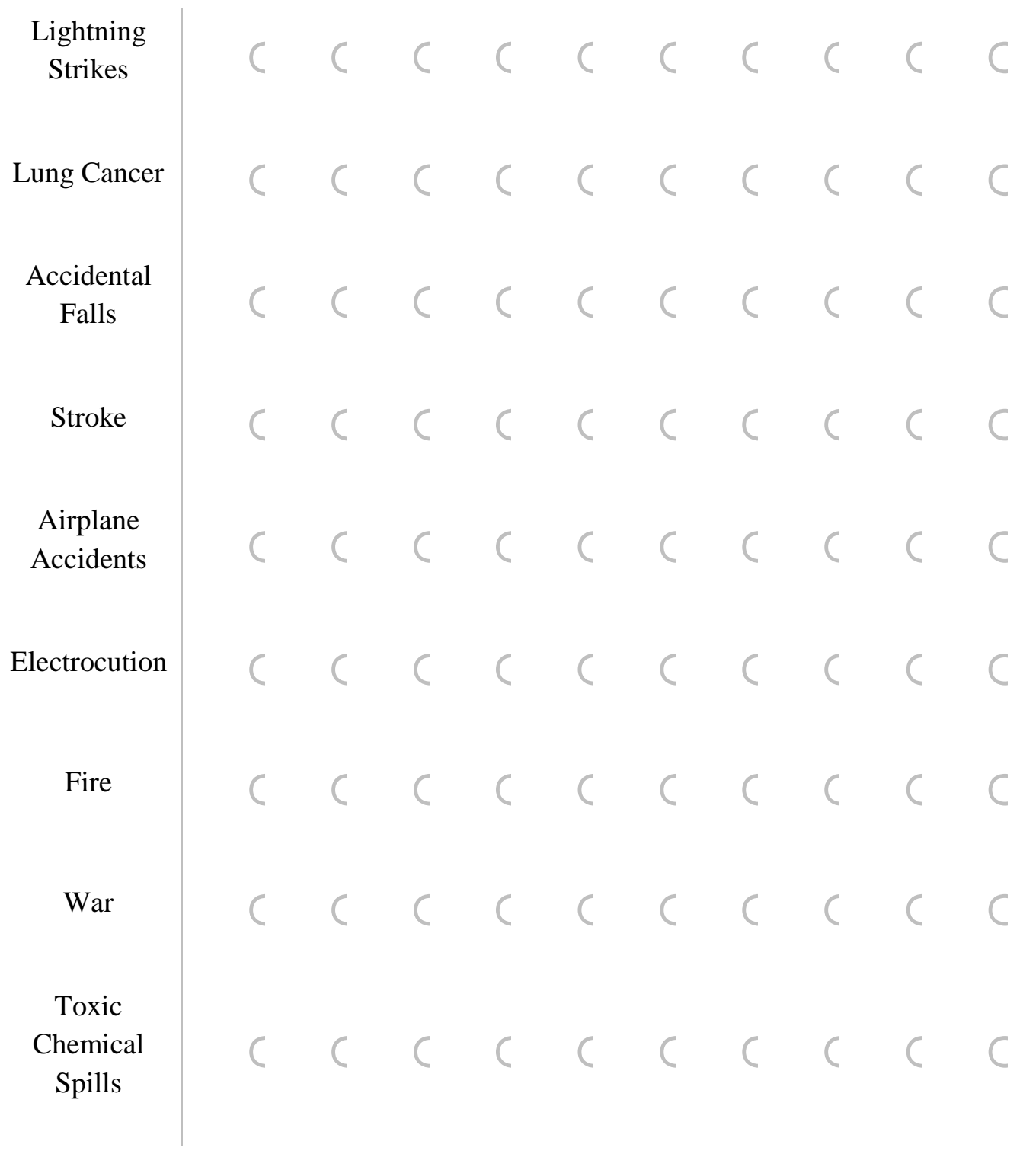


Q12 Please estimate the number of people per year in the United States who won the following prizes in 2017.

Lottery jackpot over one million dollars

Lottery jackpot over ten million dollars

A new home

A timeshare

An iPad 
Q10 Have you ever won anything by random chance (for example, a raffle prize or money from a lottery ticket)?

Yes No

Q15 You would describe your ethnicity as: (select all that apply)

White/Caucasian

Hispanic or Latino

Black or African American

Native American or American Indian

Asian / Pacific Islander

Other

Prefer not to answer 
Q16 Please select your gender.

Male

Female

Non-gendered

Prefer not to answer

Q17 In what year were you born?

Q18 Is there anything else you would like to share with us about the survey? 
Appendix C - Informed Consent Form

\section{Q1 Informed Consent Form}

You are invited to participate in a research study conducted by Derek Bonniksen under the direction of Dr. Lauren Frank. This study attempts to collect information about stylistic features of news reporting. You were selected as a possible participant in this study because you are at least 18 years old and have a positive rating on Mechanical Turk.

\section{Procedures}

If you decide to participate, you will be asked read a short newspaper article and answer questions about your reaction to it. You will then be asked to complete a questionnaire about your response to the story. The entire study will take approximately 20 minutes.

\section{Risks/Discomforts}

Risks are minimal for involvement in this study. However, you may feel uncomfortable when asked to read a personal interest story. You are welcome to skip any question that you feel uncomfortable answering.

\section{Benefits}

You may not receive any direct benefit from taking part in this study. However, it is hoped that through your participation, the study may help to increase knowledge which may help others in the future.

\section{Confidentiality}

All information that is obtained in connection with this study will be kept confidential and will only be reported in an aggregate format (by reporting only combined results and never reporting individual ones). All questionnaires will be concealed, and no one other

than the research team will have access to them. At no point will you name be linked to your answers.

\section{Compensation}

For completing this study you will receive $\$ 1.25$ as compensation to your Mechanical Turk account. 


\section{Participation}

Participation in this research study is completely voluntary. You have the right to withdraw at any time or refuse to participate entirely.

\section{Questions about the Research}

If you have questions or concerns regarding this study, contact Derek Bonniksen (dbonn2@pdx.edu) or Dr. Frank at LFrank@pdx.edu.

\section{Questions about your Rights as Research Participants}

If you have questions or concerns about your rights as a research subject, please Research and Strategic Partnerships, Market Center Building 6th floor, Portland State University, 503-725-4288. By completing this survey, you are certifying that you are 18 years of age or older, that you have read and understood the above information and agree to take part in the survey. To print this consent form on a PC, press CTRL $+\mathrm{P}$. To print this consent form on a Mac, press COMMAND + $\mathrm{P}$. If at this point you choose to continue in this research study, please click "I consent" to continue. 